\title{
Assessment and Optimization for Urban Planning Projects
}

\author{
Walid Mustafa Khamas ${ }^{1}$, Hafeth I. Naji ${ }^{2}$, Aya A. Hasan ${ }^{3}$ \\ ${ }^{1}$ Professor, Department of Cities Planning Engineering, Technical College, Technical Sulaymaniyah \\ University \\ ${ }^{2}$ Assistant Professor, ${ }^{3}$ M.Sc. Student, Department of Civil Engineering, Engineering College, \\ University of Diyala \\ aya_ali393930@yahoo.com
}

\begin{abstract}
After increasing the wheel of progress obviously in recent years in all areas, especially in urban planning projects. This led to the increasing need for a scientific and developing method to organize data processing by choosing the optimized master plan for cities. So, the importance of the process of selecting the optimized master plan of economic, environmental and social because of the indirect contact with the people, so the need arises to seek for the best methods that assist in the evaluation and selection of urban planning projects and decision-making by selecting the optimized master plan. One of the methods is the Fuzzy AHP and Fuzzy TOPSIS. This research concentrates on Fuzzy TOPSIS technique which helps to make the best decisions through choosing the optimized master plan for cities. This research aims to evaluate the alternatives to master plan of cities and select the best ones. To achieve the objectives of the research, the data collected from the literature reviews that dealt with themes of urban planning and Fuzzy TOPSIS technique as well as the personal interviews with specialists. The results showed through the data analysis of the sample that the third alternative (Muqdadiyah urban and agricultural center) has received the largest relative importance compared to other alternatives. In the end, a set of conclusions and recommendations were drawn such as the absence of an administrative system capable of evaluating and selecting the optimized master plan with less time and cost. It was found through using the technical research that time and cost of the evaluation and selection obviously significantly were reduced among the alternatives.
\end{abstract}

Corrosion inhibition of low carbon steel, stainless steel types 316 and 304 in hydrochloric acid by potassium iodide was investigated at different temperatures using weight loss and polarization electrochemical techniques
Keywords: Urban planning, Fuzzy TOPSIS, Master plan of cities.

Paper History: Received: (20/10/2016), Accepted: (12/12/2016)

\section{Introduction}

Fuzzy multi criteria decision making techniques have been developed due to the imprecision in evaluating the relative importance of criteria and the ratings of alternatives with respect to criteria. Imprecision may appear from a variety of reasons: incomplete information, unquantifiable information, partial ignorance and unobtainable information. Solving that problem thus requires criteria and the set of possible alternatives for an evaluation procedure to rank and rate, in order of preference, assessing the alternatives and choosing the optimal alternative [1].

The Order Preference by Similarity to Ideal Solution (TOPSIS) Technique was introduced by Hwang and Yoon in 1981[2]. The fuzzy TOPSIS operates on the basis that the most preferred decision alternative should have the shortest distance from a positive ideal solution (PIS), also have the farthest distance from the negative ideal solution (NIS), hence its ability and effectiveness in dealing with uncertainty is selected as optimal [3], [4].

So that this method can also be implemented on its decision making in the urban planning [5] .Select linguistic variable for alternatives with related to each criterion .then, Transform linguistic variable to fuzzy numbers [6].

\section{Objective of the Research}

This research aims to use the Fuzzy AHP and Fuzzy TOPSIS techniques to evaluate and select the optimized master plan for cities to reduce the time and cost in selecting between alternatives.

\section{Steps of the FTOPSIS Technique}

The steps of FTOPSIS are as follows [7], [8]: 
1. Assignment ratings to the criteria and the alternatives .

Where alternative $A=\{A 1, A 2, \ldots, A \mathrm{i}\}$, to be evaluated against $n$ criteria $C=\{C 1, C 2, \ldots$, $C j\}$, and the criteria weights are denoted by $w \mathrm{j}$ $\{\mathrm{j}=1,2, \ldots, \mathrm{n}\}$, then the performance ratings of each decision maker $D k\{k=1,2, \ldots, K\}$ for each alternative $A \mathrm{i}\{\mathrm{i}=1,2, \ldots, \mathrm{m}\}$ with respect to criteria $C \mathrm{j}\{\mathrm{j}=1,2, \ldots, \mathrm{n}\}$ are denoted by $R k=x i j k(i=1,2, \ldots, \mathrm{m} ; j=1$, $2, \ldots, \mathrm{n} ; k=1,2, \ldots, K)$.

2. Calculate and aggregate the fuzzy ratings for the alternatives. If the fuzzy ratings of all decision makers are described as a triangular fuzzy number $R k=(1 k, \mathrm{~m} k, \mathrm{u} k)$, then the aggregated fuzzy rating is given by $R=(1, \mathrm{~m}, \mathrm{u})$, where $k=1,2, \ldots, K$. Then the aggregated fuzzy ratings $x i j(1 i j, \mathrm{~m} i j, \mathrm{u} i j)$ [9].

3. Calculate the fuzzy decision matrix. The fuzzy performance decision matrix for the alternatives (D) is constructed as follows. This is followed by the choice of the appropriate linguistic variable for the alternatives with respect to the criteria.

$$
\widetilde{D}=\begin{gathered}
A_{1} C_{1} \\
A_{2} \\
\vdots \\
A_{m}
\end{gathered}\left[\begin{array}{cccc}
\tilde{x}_{11} & \tilde{x}_{12} & \ldots & C_{n} \\
\tilde{x}_{21} & \tilde{x}_{22} & \ldots & \tilde{x}_{1 n} \\
\cdots & \cdots & \tilde{x}_{21} \\
\tilde{x}_{m 1} & \tilde{x}_{m 1} & \cdots & \tilde{x}_{m n}
\end{array}\right]
$$

4. Normalize the fuzzy decision matrix $(\mathrm{R})^{\tilde{}}$ is given by:

$\tilde{R}=\left[\tilde{r}_{i j}\right]_{m * n}$

For $\mathrm{i}=1,2, \ldots, \mathrm{m}, \mathrm{j}=1,2, \ldots, \mathrm{n}$.

Where $\quad \tilde{r}_{i j}=\left(\frac{l_{i j}}{u_{j}^{*}}, \frac{m_{i j}}{u_{j}^{*}}, \frac{u_{i j}}{u_{j}^{*}}\right)$ and $u_{j}^{*}=$ $\max _{i} u_{i j}$

5. Computes the weighted normalized matrix. The weighted normalized matrix (Vy) for criteria is computed by:

$\check{V}=\left[\tilde{V}_{i j}\right]_{m * n}=\left[\tilde{r}_{i j}(\cdot) w_{i j}\right]$

For $\mathrm{i}=1,2, \ldots, \mathrm{m} ; \mathrm{j}=1,2, \ldots, \mathrm{n}$.

Where (wij) the weights of criteria

6. Computes the fuzzy positive ideal solution (FPIS) and fuzzy negative ideal solution (FNIS) of the alternatives are computed as follows. From the weighted normalized fuzzydecision matrix:
$A^{+}=\left(\tilde{v}_{1}^{+}, \tilde{v}_{2}^{+}, \ldots, \tilde{v}_{n}^{+}\right)$

Where $v_{j}^{+}=\max _{i}\left\{v_{i j}\right\}, i=1,2, \ldots, m ; j=$ $1,2, \ldots, n$.

$A^{-}=\left(\tilde{v}_{1}^{-}, \tilde{v}_{2}^{-}, \ldots, \tilde{v}_{n}^{-}\right)$

7. Computes the distance of each alternative from FPIS and FNIS. The distance (di+, di-) of each weighted alternative $i=1,2,3, \ldots . ., \mathrm{m}$ from the FPIS and the FNIS is computed as follows :

$$
\begin{aligned}
& d_{i}^{+}=\sum_{j=1}^{n} d_{v}\left(\tilde{v}_{i j}, \tilde{v}_{j}^{+}\right)=\left[\frac{1}{3} \sum_{j=1}^{n}\left(\tilde{v}_{i j}-\tilde{v}_{j}^{+}\right)^{2}\right]^{\frac{1}{2}}, \\
& i=1,2, \ldots, m . \\
& d_{i}^{-}=\sum_{j=1}^{n} d_{v}\left(\tilde{v}_{i j}, \tilde{v}_{j}^{-}\right)=\left[\frac{1}{3} \sum_{j=1}^{n}\left(\tilde{v}_{i j}-\tilde{v}_{j}^{-}\right)^{2}\right]^{\frac{1}{2}}, \\
& i=1,2, \ldots, m .
\end{aligned}
$$

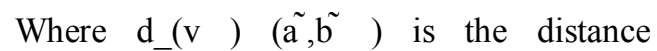
measurement between two fuzzy numbers $\tilde{a}$ and $\tilde{b}$.

8. Computes the closssness coefficient (CCi) of each alternatives. The closeness coefficient (CCi) is computed as:

$C C_{i}=\frac{d_{i}^{-}}{d_{i}^{-}+d_{i}^{+}}=\left(1-\frac{d_{i}^{+}}{d_{i}^{-}+d_{i}^{+}}\right)$

for $i=1,2, \ldots, m$

9. Ranking the alternatives. The different alternatives are ranked according to the closeness coefficient (CCi) in decreasing order. The best alternative is closer to the FPIS and farthest from the FNIS.

\section{Urban Planning}

Urban planning as a conventional instrument in investigation a balance between different aspects such as the economic, environmental, social, and governance aspects, then promoting interaction among city planners , officials , and the local community [10] . Furthermore, urban planning procedures are utilized as a part of the assessment of the social, economic, and environmental effects of urban policies. They take into consideration a deliberate investigation of the relationship between social, economic, and environmental advancements, which portrays the shared reliance between urban planning and sustainable development [11]. As such, city planning should be based on the principle of sustainability, in order to achieve sustainable urban development. 
Meanwhile, urban planning ought to be a reaction to the worldwide changes and patterns influencing urban communities, particularly in the developing Countries. Those vital urban planning frameworks created in the previous decades comprised of structures connected with an arrangement of indicators which assessed the supportability of the city's polices [11] . While, that urban planning is the investigation of managing, guiding and coordinating city development. Urban, city, or town planning is controlling of land use planning which investigates an extensive variety of parts of the built environment for municipalities and urbanised regions [12].

\section{Benefits of Sustainable Urban Planning}

The advantages of the use of new urbanism are for the client or tenant, as well as for designers, organizations and governments the following below shows the major types of benefits and the detailed points for each one[13]:

\section{Benefits for Inhabitants}

1. Better personal satisfaction in life.

2. Less traffic congestion from vehicles.

3. The quality of life is better with less effort.

4. Better workplaces and recreational areas.

5. Better displacement from one location to another.

\section{Benefits for Businesses}

1. Increase in trades because of more pedestrians in urban communities

2. Less fatigue in supplying every client. 3. Saving cash on transportation. 4. Rental costs diminish in business zones and an expansion in open doors for small and large businesses.

\section{Benefits for Developers}

1. Better chances for real-estate development because of the expansion of population density and the arranging of cities .

2. Cost reserve funds because of efficient, in the urban areas that receive smart development 3. Less requirement for parking zones because of an expansion in people on foot. 4. Reduction of effect on infrastructure because of a decrease in the utilization of cars .

\section{Benefits for Local Governments}

1. Better view and identity of the community or city.

2. More steadiness in the installment of taxes
3.Less danger in unnecessary or perilous urban development

4. Decrease in costs for environmental effect . 5.Less per-capita cost for infrastructures compared with conventional urbanism.

6. Less vehicle traffic .

\section{Master Plan of AL- Muqdadiyah}

Al-Muqdadiyah city is the center of AlMuqdadiyah district where it located in Diyala governorate at the northeast of the Baqubah city with a distance of 41 Kilometers, and away from the city of Baghdad, about 110 Kilometers north-east and has a local named (Shahraban), its area is 1046 square kilometers, and thus accounted for up to $5.81 \%$ of the Diyala governorate, in what constitutes the center of Muqdadiya accounted for $4.32 \%$ of the governorate area [14] . Al-Muqdadiyah city is considered as a major transit point in the governorate between districts and areas which are located in the east and west of the governorate. Also it is considered as the pathway that connects Diyala governorate center within Kirkuk governorate and the northern governorates, which means that the location of Al- Muqdadiyah urban center has an important spatial development policy in Iraq .

\section{Future Development Alternatives}

Three development alternatives are put an attempt to achieve diversity and integration .It has been obtaining information from official authorities, Each alternative will be explaining in detail as follows:

\section{The First Alternative (Al-Muqdadiyah Commercial Center)}

This alternative is based on the important strategic of Al-Muqdadiyah city within its regional environment (its relationship Diyala governorate and other governorates), where the geographical location of Al-Muqdadiyah city strengthened its commercial location other than it is being located on the main road linking Iran to Baghdad as well as the cities of Khanaqin, Sulaimaniya and Kalar which directed for Baghdad and Baqubah. AlMuqdadiyah city is considered as a commercial center for all villages in the Hamrin basin.

\section{A. Basic Pillars of the Alternative}


The first alternative is based on the development of the city in terms of:

1. Strong economic growth that activating the industry to be the base for economic development 2 .. Developing the old part of the city and strengthening the role of the center to create a contemporary, sophisticated and vibrant city. 3 Creating an area (entertainment - cultural) along with the riverbank, as well as the establishment of a series of green areas and use it as public parks. 4 . Creating environmental treatments is related by establishing an agricultural area around the industrial zone as a greenbelt. 5. Developing light and medium industries in the southern region of the city also put trade in the area around the train station in Al-Atha'aa area. 6 . Establishing a network of new roads and connect them with old one after its development, in order to reduce the momentum on major roads, including the tourist road and so as to enhance regional connectivity. Building up two bridges to link the two banks of the Mehrot River with the city. The alternative reinforces road network through linking the current city parts and expansion areas within an annular highway which is formed at the same time the limits of the master plan. Alternative treats traffic problems within the city through an annular path aligns the city center and binds the other parts of the city.

\section{The Second Alternative (Integrated Regional Center)}

The current alternative confirms the need of Al- Muqdadiyah city to have a vital and active role in the field of tourism and recreation.

\section{A. Basic Pillars of the Alternative}

1. The alternative vision of the city as an integrated regional center provides all kinds of services and facilities not only for the city and Al-Muqdadiya district only but for the whole Diyala governorate.

2. Improving the city's environment.

3. Expanding and developing the economic base of the city, through the development of industrial, commercial, and tourism sectors. 4. Providing future housing needs, social services and making places of entertainment for the city's residents in different spaces with a variety of formats.

5. Improving and developing of infrastructure services as a network of roads and others.

6. Taking advantage of the river interface, and using them to promote recreational and tourism activities .

\section{The Third Alternative (Al-Muqdadiyah Urban and Agricultural Center)}

This alternative is based on the agricultural capabilities of Al-Muqdadiyah city and surrounding areas. The use of environment surrounding to get optimal benefit from it. So, Al-Muqdadiyah city must take the leadership role represented by the economic process (agriculturally - industrially), which converts agricultural crops to canned products, which lead to improve the economic situation of the city.

\section{A. Basic Pillars of the Alternative}

The vision of an alternative is to making the city of Al-Muqdadiyah green city and the emphasis on the development of urban areas through:

1. Maintaining agricultural areas and the expansion is mainly south of the city to resolve an important aspect of the environmental problems of the city where this expansion will be a solution to the problem of sand dunes in Al-Atha'aa area.

2. Enhancing the city center to determine commercial and cultural uses of the task in order to create a vital model of the city center in which there is a space for entertainment, and buildup of the administrative buildings on both sides of the center which are not inconsistent with the multiple uses of the city center.

3 . Recruiting and investment the riverbank of Al-Shakhah, constructing new green spaces, parks and a number of lakes.

4. Reinforcing the city's economy through allocating suitable area for industrial use in order to achieve the following:

A. Exceeding the environmental problems of establishing industrial parks and providing a green insulation zone between industrial use and other uses. B. Deporting industrial uses and industrial services to the proposed location to insurance the urban landscape and to improve the environmental situation within the city

5. Specifying spaces for the expansion of urban residential on the north-east and east, southwest and west of the city and taking into account the provision of all infrastructure services

6. Emphasizing on road network especially in solving transportation problems within the city through two levels of the proposed ring roads, the first connects the inner parts of the city, while the second will be at city suburbs and set up a number of proposed bridges. 
An application of FTOPSIS Technique in the Process Evaluation and Selection the Master Plan of AL- Muqdadiyah City

Through these obtained data from the questionnaire the accounts of FTOPSIS technique are done as follows:

1. Comparing alternatives according to the criteria Data was collected from experts in the field of specialization to choose the optimized master plan for cities. The sample number was 38 expert and a part of the questionnaire shown in Appendix (1), where the 38 experts answers were grouped and placed in the Table 1 .

Table 1 Aggregate decision making matrix.

\begin{tabular}{|c|c|c|c|c|c|}
\hline $\begin{array}{l}\mathbf{C} \\
\mathbf{A}\end{array}$ & है. & 象 & $\begin{array}{l}\mathscr{2} \\
\stackrel{0}{0} \\
\text { @. }\end{array}$ & 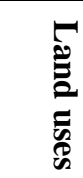 & 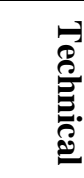 \\
\hline A1 & 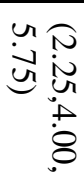 & 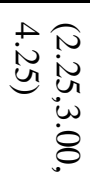 & 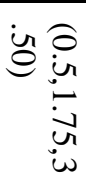 & 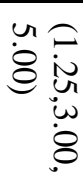 & $\begin{array}{r}1 \\
\dot{8} \\
\dot{8}\end{array}$ \\
\hline A2 & 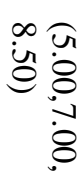 & 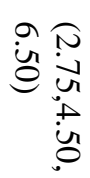 & 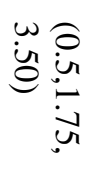 & 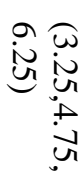 & 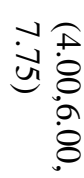 \\
\hline $\mathbf{A 3}$ & $\underbrace{\infty}_{\substack{u \\
\sim}}$ & 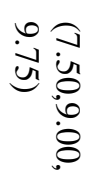 & 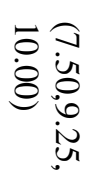 & 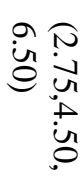 & 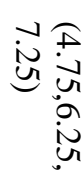 \\
\hline $\begin{array}{l}\text { Max } \\
\text { of } \\
\text { uppe } \\
\mathbf{r} \\
\text { limit }\end{array}$ & 8.50 & 9.75 & 10.0 & 6.50 & 7.75 \\
\hline
\end{tabular}

\section{Calculating normalized decision matrix}

Equation (2) has been applied on the decision matrix as it shown in Table 1 and produced normalized decision matrix as it shown in Table 2. Depending on the relative importance of the criteria that has been extracted from FAHP (Fuzzy Analytic hierarchy process) technique, relative importance of the five criteria and has been used to choose between alternatives are as follows : economic (0.183), environmental (0.165), social (0136), land uses (0.421) and technical (0.096).
Table 2 Normalized decision matrix with weight of each criterion.

\begin{tabular}{|c|c|c|c|c|c|}
\hline $\begin{array}{l}\mathbf{C} \\
\mathbf{A}\end{array}$ & ह̂. & 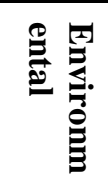 & 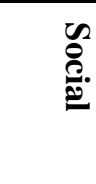 & 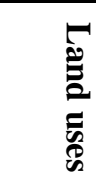 & 节. \\
\hline A1 & 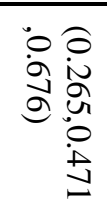 & 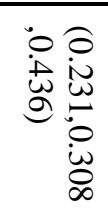 & 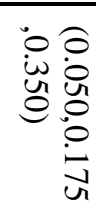 & 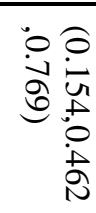 & 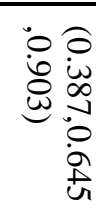 \\
\hline A2 & 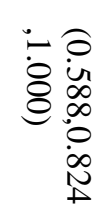 & 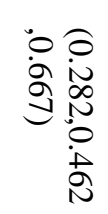 & 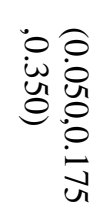 & 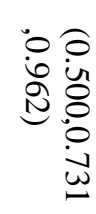 & 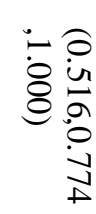 \\
\hline A3 & 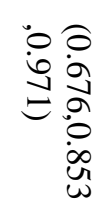 & 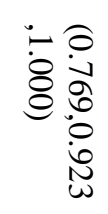 & 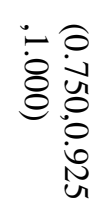 & 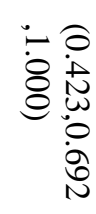 & 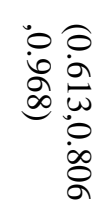 \\
\hline 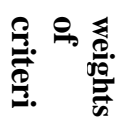 & 0.183 & 0.165 & 0.136 & 0.421 & 0.096 \\
\hline
\end{tabular}

3. Calculating the weighted normalized decision matrix

A weighted normalized decision matrix is calculated within FTOPSIS technique and also here two techniques are merged at the same time to reach the right decision in the process of selecting optimal master plan by applying Equation (3) on the normalized decision matrix as it shown in Table 2 and produced a weighted decision matrix, as shown in the Table 3.4 . Determining the negative ideal solution and the positive ideal solution

The positive ideal solution as well as the negative ideal solution are calculated by applying Equations (4), (5), (6) and (7) on the weighted normalized decision matrix in the Table 3 and thereby the obtained results it shown in Table 4 and Table 5.

5. Calculating the relative closeness to the ideal solution and arranging alternatives. Based on the results obtained from the previous steps of the technique applied (FTOPSIS), the relative proximity is calculated according to the ideal solution and the order of the alternatives in order of preference and through the application of Equation (8) on the results which are shown in Table 4 and Table 5 to obtain the final result represented by the Table 6 and Table 7. 
Table 3 Weighted normalized decision making matrix.

\begin{tabular}{|c|c|c|c|c|c|}
\hline $\mathrm{C}$ & ○ & 四 & 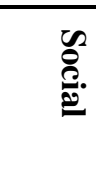 & 密 & - \\
\hline$\overline{\mathrm{A1}}$ & $\begin{array}{l}\infty \\
20 \\
0 \\
0 \\
0 \\
N \\
\pm\end{array}$ & 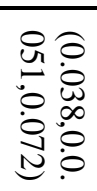 & 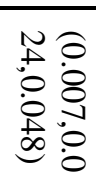 & 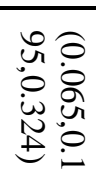 & 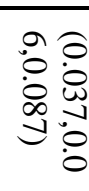 \\
\hline A2 & 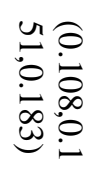 & $\begin{array}{l}\sqrt{d} 0 \\
0 \\
0 \\
0 \\
0 \\
0 \\
0\end{array}$ & 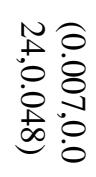 & 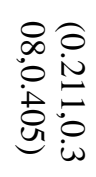 & $\begin{array}{l}1 \\
+0 \\
0 \\
0 \\
0 \\
0 \\
0 \\
0\end{array}$ \\
\hline A3 & $\begin{array}{l}\text { La } \\
0 \\
0 \\
0 \\
\vdots \\
\infty \\
\infty\end{array}$ & 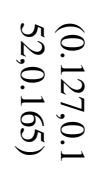 & 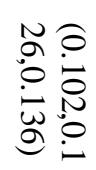 & 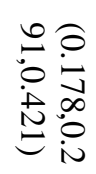 & 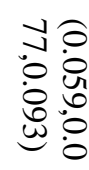 \\
\hline
\end{tabular}

Table 4 Distance between $\mathrm{Ai}(\mathrm{i}=1,2,3)$ and $\tilde{v}_{j}^{+}$with respect to each criterion $(\mathrm{C} 1, \mathrm{C} 2, \mathrm{C} 3$ , C4, C5 ).

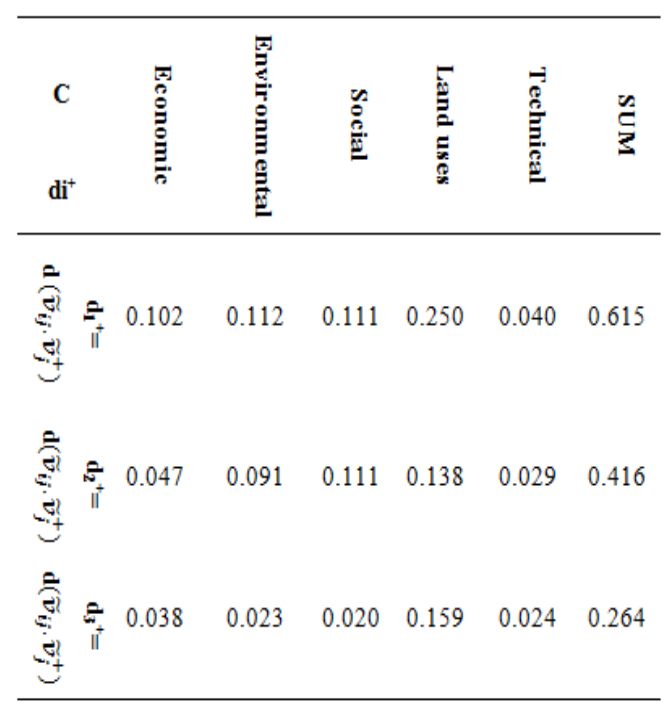

Table 5 Distance between $\mathrm{Ai}(\mathrm{i}=1,2,3)$ and $\widetilde{\boldsymbol{v}}_{\boldsymbol{j}}^{-}$with respect to each criterion ( $\mathrm{C} 1, \mathrm{C} 2, \mathrm{C} 3$ , C4, C5 ).

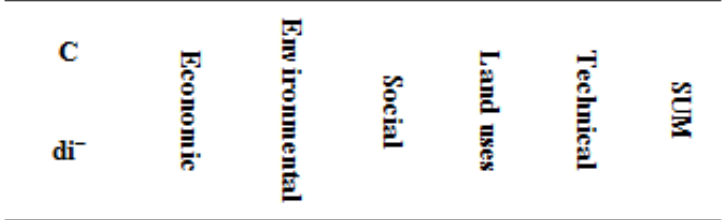

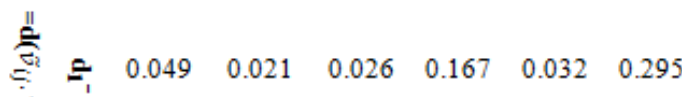
$\underbrace{-3}_{i}$

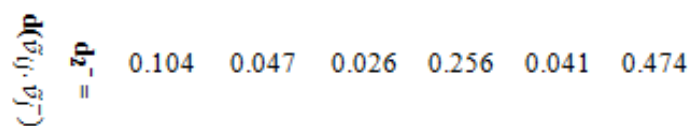

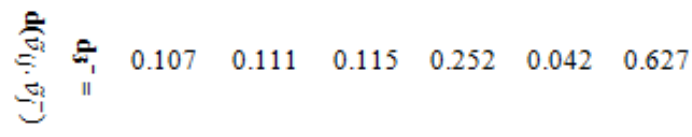

Table 6 Closeness coefficient of alternatives (CCi).

\begin{tabular}{|c|c|c|c|c|}
\hline & di+ & $\mathrm{di}^{-}$ & $\mathrm{di}^{-}+\mathrm{di}+$ & 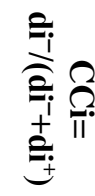 \\
\hline A1 & 0.615 & 0.295 & 0.910 & 0.324 \\
\hline A2 & 0.416 & 0.474 & 0.890 & 0.533 \\
\hline A3 & 0.264 & 0.627 & 0.891 & 0.704 \\
\hline
\end{tabular}

Table 7 The ranking of alternatives.

\begin{tabular}{ccc}
\hline Alternatives & CCi & Rank \\
\hline A1 & 0.313 & 3 \\
A2 & 0.514 & 2 \\
A3 & 0.700 & 1 \\
\hline
\end{tabular}




\section{Analysis and Discussion of the Result FTOPSIS technique}

1. The alternative (Commercial center (A1)) received $(32.4 \%)$ according to the distribution of industrial and commercial activities, the alternative is good compared with other alternatives. This alternative provides a good connect of internal and external roads. But the vision of this alternative is not sufficient because of the strong focus on the development of the economic side only. Where this alternative received less relative importance among the alternatives.

2. The alternative (Integrated regional Center (A2)) received $(53.3 \%)$ is the best in meeting the basic needs, developing economic development, creating attractive public spaces and improving the regional development process. Where the alternative obtained medium importance according to other alternatives.

3. The optimal alternative is (A3) (Urban and agricultural center) is more important than the rest of alternatives where it received $(70.4 \%)$ because it is being the closest to the ideal solution and obtained the first place among other alternatives. The alternative is the best in the establishment of a green city, improving the transport network, improving regional development. Where this alternative received the highest relative importance among the alternatives, as it shown in the Figure 1.

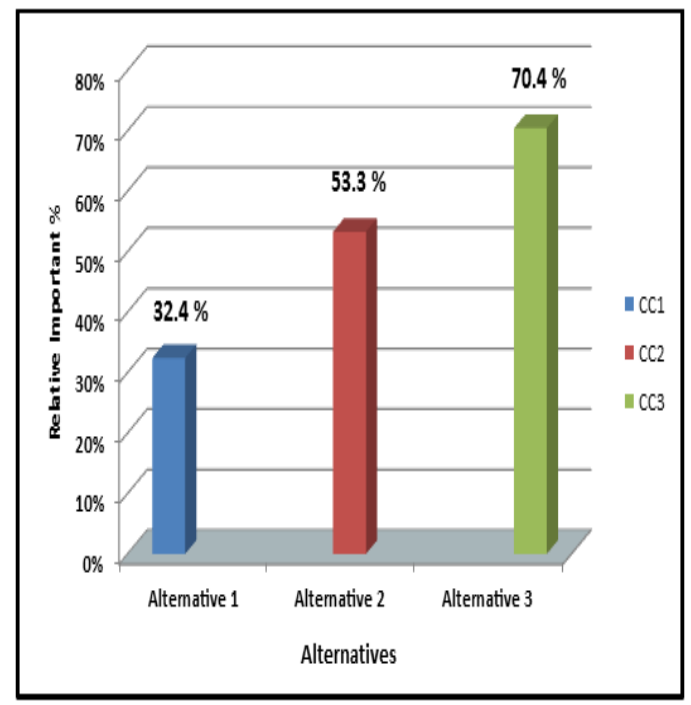

Figure 1: The ranking of alternatives by $\mathrm{CCi}$ in descending order (by Fuzzy TOPSIS)

\section{Conclusions}

1. The process of selecting the optimized master plan for cities have a major impact on the goals of the stakeholders in future projects establishment (as projects of infrastructure and housing ... etc.) in terms of time and cost less.

2. The results showed that the use of Fuzzy AHP and Fuzzy TOPSIS techniques accelerate the process of selecting the optimized master plan, rather than specialists decision makers who spend long time in the selection of a master plan as well as the comparison between the main plans submitted and thus shorten the time needed to complete the selection process.

3. Absence of an efficient administrative system capable of addressing the weaknesses by providing the necessary data and information that will help the various administrative levels in the control and followup when the implementation of the projects.

\section{Recommendation}

The recommendations can achieve the objective of the research, as follows:

1. The need to establish working courses for those who work in this area to make them know about the modern methods of decisionmaking which include Fuzzy AHP and Fuzzy TOPSIS.

2. The need to integrate the techniques to get accurate results and that what has been achieved through research.

3. Provide the base data and information on the projects implemented by the competent governmental authorities of the various administrative levels, and the use and development of knowledge -based electronic system and documents.

\section{Acknowledgment}

This work was supported by Diyala University, Civil Engineering Department, which is gratefully acknowledged.

\section{References}

[1]. Mohaghar,A., Fathi , M. R., Zarchi, M. K. and Omidian, A., A combined VIKOR - Fuzzy AHP approach to marketing strategy selection, Business Management and Strategy, 3(1), (2012), 13-27.

[2]. Shukla, R. K., Garg, D. and Agarwal, A. An integrated approach of Fuzzy AHP and Fuzzy TOPSIS in modeling supply chain 
coordination, Production \& Manufacturing Research, 2(1), (2014), 415-437.

[3]. Ouma, Y. O., Opudo, J. and Nyambenya, S. Comparison of Fuzzy AHP and Fuzzy TOPSIS for road pavement maintenance prioritization: Methodological exposition and case study, Advances in Civil Engineering, (2015), 1-17.

[4]. Ertugrul, I. and Karakasoglu, N. Performance evaluation of Turkish cement firms with fuzzy analytic hierarchy process and TOPSIS methods, Expert Systems with Applications, 36 (1), (2009), 702-715 .

[5]. Masoumi, I., Naraghi, S., Rashidi-nejad, F. and Masoumi, S. Application of fuzzy multiattribute decision-making to select and to rank the post-mining land-use, Environmental Earth Sciences,72(1), (2014), 221-231 .

[6]. Moradpour, S.,Ebrahimnejad, S., Mehdizadeh ,E. and Mohamadi ,A. Using hybrid fuzzy PROMETHEE II and fuzzy binary goal programming for risk ranking: A case study of highway construction projects, Journal of Optimization in Industrial Engineering, 9, (2011), 47-55 .

[7]. Jahanshahloo, G. R., Lotfi, F. H. and Izadikhah, M. An algorithmic method to extend TOPSIS for decision-making problems with interval data, Applied Mathematics and Computation, 175(2), (2006), 1375-1384 .

[8]. Ashrafzadeh, M., Mokhatab, F. R. and Mollaverdi, N. I. Application of fuzzy TOPSIS method for selection of warehouse location: A case study. Interdisciplinary, Journal of Contemporary Research Business, 3(9), (2012), 655-671.

[9]. Sun, C.-C. A performance evaluation model by integrating fuzzy AHP and fuzzy TOPSIS methods, Expert Systems with Applications, 37(12), (2010), 7745-7754 .

[10]. Diamantine, C. and Zanon, B. Planning the urban sustainable development: The case of the plan for the province of Trento, Italy, Environmental Impact Assessment Review, 20(3), (2000), 299-310 .

[11]. Rotmansa, J., Asselt, M. v. and Vellinga, P. An integrated planning tool for sustainable cities, Environmental Impact Assessment Review, 20(3), (2000), 265-276.

12. Pleho, J. and Avdagic, Z. Fuzzy model in urban planning, Proceeding FS'08 Proceedings of the 9th WSEAS International Conference on
Fuzzy Systems, Sofia, Bulgaria, (2008), 156160.

13. Hernández-Moreno,S. and DeHoyosMartínez, J. Indicators of urban sustainability in Mexico, Theoretical and Empirical Researches in Urban Management, 7(16), (2010), 46-60.

14. Central Organization for Statistics and Information Technology, Ministry of Planning, Republic of Iraq. 